|| ISSN(online): 2589-8698 || ISSN(print): 2589-868X || International Journal of Medical and Biomedical Studies

Available Online at www.ijmbs.info

PubMed (National Library of Medicine ID: 101738825)

Index Copernicus Value 2018: 75.71

Original Research Article

Volume 3, Issue 5; May: 2019; Page No. 215-218

\title{
STUDY OF PREVALENCE OF DEPRESSION AMONG HYPERTENSIVE AND DIABETIC SUBJECTS
}

\section{Dr. Akshay Berad ${ }^{1 *}$, Punam R Pal ${ }^{2}$, Dr. N.P. Veenavani ${ }^{3}$}

$1^{*}$ Associate Professor, Dept. of physiology, RIMS, Adilabad, Telangana, India.

${ }^{2}$ Research Scholar, Dept. of Pharmacy Practice, JJTU Jhunjhunu, Rajasthan, India.

${ }^{3}$ Assistant Professor (Psychology) Sri Balaji college of Physiotherapy, BIHER, Chennai, Tamil Nadu, India.

Article Info: Received 01 May 2019; Accepted 30 May. 2019

DOI: https://doi.org/10.32553/ijmbs.v3i5.274

Corresponding Author: Dr. Akshay Berad, Associate Professor, Dept. of physiology, RIMS, Adilabad, Telangana, India

Conflict of interest: No conflict of interest.

\section{Abstract:}

Introduction: Hypertension, Diabetes mellitus and depression are among the group of the most common chronic diseases worldwide, and according to numerous studies they are oftentimes associated. Patients suffering from lifestyle diseases may have increased depression levels in relation with long-term management of these diseases. This study was conducted to determine the prevalence of depression among diabetes mellitus and hypertensive patients.

Materials and methods: A cross-sectional research design was adopted for the study. The study was conducted in a tertiary care hospital. 100 subjects were included in study. Patients were given preformed proforma to fill the data regarding socio-demographic profile and status of diabetes mellitus and hypertension. Major depression inventory tool was used to assess depression.

Results: Study shows out of 100 subjects 44 subjects were having depression and 56 subjects were nondepressed. $37.5 \%$ of diabetic subjects were having depression. $43.75 \%$ of hypertensive subjects were having depression. $60 \%$ of subjects those who were suffering from hypertension and diabetes both were depressed. Conclusion: The prevalence of depression is high in patients with diabetes and has a considerable impact on the consequences of diabetes and quality of life too.

Keywords: Hypertension Diabetes mellitus, Depression.

\section{Introduction}

Hypertension and depression are among the group of the most common chronic diseases worldwide, and according to numerous studies they are oftentimes associated. Patients with chronic illnesses, such as e.g. hypertension, may experience negative emotions that in these patients increase the risk of mental disorders, most commonly depression and anxiety disorders [1, 2]. According to a survey by the World Health Organization (WHO), conducted in 17 countries, for every 20 people one person had a depressive episode in the past. It is assumed that depression affects about 350 million persons worldwide [3]. It is estimated that worldwide one in four adults has hypertension, and it is anticipated that the rising prevalence by 2025 is to result with every third adult with hypertension [4]. Many people with diagnosed hypertension have somatic complaints, poor quality of life and disturbances in daily functionality [5]. There has been a surge in lifestyle diseases in the past few years, especially diabetes mellitus and hypertension. This is due to increased urbanization, intake of more processed, packaged foods, increasingly stressful lifestyles and absence of physical activity, among others reasons[6], Genetic causes also play a very important role. Observing the pathophysiological mechanism of depression and hypertension, over-reactivity of the sympathetic nervous system is present in both diseases. The influence of genetic factors in developing both diseases has a very important role and can explain the mechanism of the association between hypertension and depression. The use of antidepressant drugs may affect the control of blood pressure in patients with hypertension, including changes in blood pressure and orthostatic hypotension [7]. Although the results of numerous 
studies have shown that there is a mutual link between hypertension and depression, there are still scarce data on the overall prevalence of depression in patients with hypertension [8]. Most of the time, depression is not considered an important factor, often ignored and left untreated [9]. To muddle through the everyday tribulations involved in supervision and handling of disease is barely challenging for patients but parallel for caretakers and healthcare professionals [10]. Therefore, based on the review of Literature researcher identified that depression is contributing factor to mortality, morbidity and increase health care costs and many times physicians are unable to identify depression in patients with Diabetes Mellitus and hypertension . So for the integrated management of comorbidity of depression with Type 2 Diabetes mellitus, it is necessary to carry out this study. Diabetes and depression are chronic debilitating conditions that are associated with high rates of complications and death. People with diabetes who have depression often find it more difficult to follow diabetes treatment recommendations and have poor metabolic control.

They have also higher complication rates, increased health care use, and increased disability, lost productivity, lower quality of life and increased risk of death [11]. Biologists and epidemiologists identify depression as both a cause and consequence of diabetes. While medical social scientists have elucidated some of the complex socioeconomic and psychophysiological pathways linking the two chronic conditions [12]. Diabetes mellitus is associated with doubled risk for comorbid depression compared to healthy controls, hampering the patient's quality of life [13].

\section{MATERIALS AND METHODS:}

A cross-sectional research design was adopted for the study. The study was conducted in a tertiary care hospital. 100 subjects were included in study. Both inpatients and out-patients were included in the study. Patients who were above 18 years of age, who had either diabetes mellitus, or hypertension, or both, were selected for the study. Patients in the casualty ward, post-operative patients, pediatric patients, patients with type 1 diabetes and patients with known psychiatric disorders were excluded from the study. Depression was assessed by using Major Depression Inventory.

\section{Data collection procedure}

Patients were given preformed proforma to fill the data regarding socio-demographic profile and status of diabetes mellitus and hypertension. Major depression inventory tool was used to assess depression. The duration of the interview was 10minutes and taken in a single sitting.

The demographic variables considered were age, gender, duration of diabetes, presence of hypertension. Age was measured in completed years. Duration of diabetes and hypertension were taken from the patients. Hypertension was defined in the study as systolic BP level of $\geq 140 \mathrm{mmHg}$ and diastolic BP of $\geq 90 \mathrm{mmHg}$, or current treatment for hypertension with prescription medication. The questions were explained to them, and the patient's response was marked by the researcher. Patients were comfortable and encouraged to speak freely.

The research results were statistically analysed by the data from the questionnaires entered into the Excel database, and then statistically analysed

Results:

Table 1: Gender wise distribution of subjects

\begin{tabular}{|l|l|}
\hline Gender & Number of subjects (100) \\
\hline Male & 34 \\
\hline Female & 66 \\
\hline
\end{tabular}

Table 1 shows out of 100 subjects 34 were males and 66 were females.

Table 2: Distribution of Patients with Hypertension and Diabetes Mellitus

\begin{tabular}{|l|l|}
\hline Disease & Number of subjects(100) \\
\hline Hypertension & 32 \\
\hline Diabetes & 48 \\
\hline Both & 20 \\
\hline
\end{tabular}

Table 2 shows out of 100 subjects, 32 had hypertension, 48 had diabetes mellitus and 20 subjects had both hypertension and diabetes mellitus. 
Table 3: Distribution of subjects having Depression

\begin{tabular}{|l|l|l|}
\hline $\begin{array}{l}\text { Variable } \\
100 \text { subjects }\end{array}$ & $\begin{array}{l}\text { Depressed } \\
\text { Number of subjects (44)(percentage) }\end{array}$ & $\begin{array}{l}\text { Non-depressed } \\
\text { Number of subjects (56)(percentage) }\end{array}$ \\
\hline Diabetes mellitus (48) & $18(37.5 \%)$ & $30(62.5 \%)$ \\
\hline Hypertension (32) & $14(43.75)$ & $18(56.25 \%)$ \\
\hline Both (20) & $12(60 \%)$ & $8(40 \%)$ \\
\hline
\end{tabular}

Table 3 shows that out of 100 subjects 44 subjects were having depression and 56 subjects were nondepressed. $37.5 \%$ of diabetic subjects were having depression. $43.75 \%$ of hypertensive subjects were having depression. $60 \%$ of subjects those who were suffering from hypertension and diabetes both were depressed.

\section{Discussion:}

The present study shows that out of 100 subjects 44 subjects were having depression and 56 subjects were non-depressed. $37.5 \%$ of diabetic subjects were having depression. $43.75 \%$ of hypertensive subjects were having depression. $60 \%$ of subjects those who were suffering from hypertension and diabetes both were depressed.

Numerous authors conducted researches in order to determine the presence of hypertension in patients with depression. So Dhar and his associates conducted a study in order to examine the incidence of cardiovascular diseases in patients with depression. The results showed that depression and stress were important independent risk factors for cardiovascular diseases. Most common cardiovascular disease in patients with depression was hypertension [14]. A large research was conducted on the relationship between depression and hypertension, which included 9,182 women of middle age, which were followed as long as 15 years, and it showed that hypertension has been in followup period developed in 2,738 women diagnosed with depression. The authors concluded that there was a frequent comorbidity between hypertension and depression. Large sectional study was conducted in India with the objective to investigate comorbidity among diabetes, hypertension, anxiety and insomnia. Study was included 2,276 patients across 18 states in India. This study demonstrates high prevalence of depression among employed and educated adult Indian patients, and hypertension and diabetes are the two most common comorbidities in patients with depression [15]. High prevalence of comorbidity of depression with diabetes in patients indicates that effect of depression

comorbidity on the quality of life can significantly affect outcomes of the disease, and early diagnosis of depression can improve quality of life [16]

\section{CONCLUSION:}

From study it can be concluded that depression is common amongst hypertensive and diabetic subjects. To alleviate their suffering and provide better healthcare, medical professionals need to implement new strategies to address mental health issues among patients with life style diseases. Detailed psychiatric assessments, pharmacotherapy and psychotherapy from a psychiatrist and psychologists could go a long way in improving the patient's mental and physical status, thereby greatly improving quality of life. Further research in this regard is also necessary to identify and acknowledge the widespread neglect of depression.

\section{REFERENCES:}

1. Kearney PM, Whelton M, Raynolds K, Murtner P. Global trends of hypertension analysis of worldwide data. Lacet. 2005; 365:217-23.

2. DeJean D, Giacomini $M$, Vanstone $M$, Brundisini F. Patients experiences of depression and anxiety with chronic disease: a systematic review and quantitative meta-synthesis. Ont Health Techol Assess Ser. 2013;13(16):1-33.

3. World Health Organization, Sixty-fifth world health assembly, 2012. http://apps.who.int /gb/DGNP/pdf_files/A65_REC1-en.pdf

4. Mittal BV, Singh AK. Hypertension in the developing world: challenges and opportunities. Am J Kidney dis.2010; 55:590-98.

5. Almas A, Patel J, Ghori U et al. Depression is linked to uncontrolled hypertension: a casecontrol study from Karachi, Pakistan. J Ment Health. 2014; 23:292-96.

6. SH Yarahmadi, K Etemad, AR Mahdavi,Hazaveh, and $\mathrm{N}$ Azhang. Urbanization and Non- 
Communicable Risk Factors in the Capital City of 6 Big Provinces of Iran. Iran J Public Health. 2013; 42(Supple1): 113-118. Published online 2013 Jan 1

7. Scalco AZ, Scalco MZ, Azul JB, Lotufo Neto F. Hypertension and depression. Clinics (San Paulo). 2005;60(3):241-50.

8. Ried LD, Tueth MJ, Handberg E et al. Validation a selfreport measure of global subjective wellbeing to predict adverse clinical outcomes. Qual Life Res. 2006; 15:675- 86.

9. Abbas A, Nasir H, Zehra A, Noor A, Jabbar FA, et al. (2015) Assessment of depression as comorbidity in diabetes mellitus patients using Beck Depression Inventory II (BDI II) scale. J Young Pharm 7: 206-216.

10. Javed S, Maqsood A (2015) Diabetes associated distress: Implications for coping and treatment. Appl Psychol 12: 1-19.

11. Kaveeshwar SAJC (2014) The current state of diabetes mellitus in India. Australas Med J 7: 4548.
12. Mendenhall E, Weaver $\sqcup$ (2014) Reorienting women's health in low- and middle-income countries: The case of depression and Type 2 diabetes. Glob Health Action 7: 1-4.

13. Pouwer $F(2010)$ Does emotional stress cause type 2 diabetes mellitus?A review from the European Depression in Diabetes (EDID) Research Consortium. Discov Med 45: 112-118.

14. Dhar AK, Barton DA. Depression and the Link with Cardiovascular Disease. Front Psychiatry. 2016; 7:33.doi: 10.3389/fpsyt.2016.00033. eCollection 2016

15. Newale S, Bachani DS. Detection, Management Approach of Depression and Antidepressant Utilizationin Adult Patients: Results of a CrossSectional Survey. J Assoc Physicians India. 2016; 64(10):52-57.

16. Eren I, Erdi O, Sahin M. The effect of depression on quality of life of patients with type II diabetes mellitus. Depress Anxiety. 2008;25(2):98-106. 